\title{
A Psychological Study of Relationship Between Dysfunctional Attitude and Self-esteem in Committing Suicide
}

\author{
Reza Jarchi \\ Islamic Azad University, Zanjan Branch \\ Mostafa Shahiditabar \\ Imam Sadiq (a. s.) University \\ Servat Shahiditabar \\ Payam Noor University, Mahneshan Branch \\ M_shahidi2005@yahoo.com
}

\begin{abstract}
Suicide is the act or an instance of taking one's own life voluntarily and intentionally especially by a person who has no aim to continue his/her life. This study is concerned with the case of suicide who wanted to kill herself by means of a bowl of liquid (combination of pesticide, oil and some drugs) with the symptom of low self-esteem. in the case of methodology, The Dysfunctional Attitude Scale (DAS) is used to measure the attitude of the subject. Coopersmith Self-Esteem Inventory is also used for measurement of self-esteem of the subject. Also some interviews were conducted with the subjects' school teachers and family. The results of the study show that the subject has low self-esteem and her cognitive misunderstandings are higher than normal. This study also confirms that high cognitive misunderstandings as well as low self-esteem causes suicide.
\end{abstract}

Keywords:Self-esteem, Dysfunctional Attitude, Suicide, Zanjan, Mahneshan

\section{Introduction}

Suicide occupies a central role in psychiatric researches in recent years. It is defined as the act of intentionally causing one's own death (Amos \& Appleby, 2001).. According to the World Health Organization, about 850000 people die by suicide in 2005, making it the 10th leading cause of death worldwide. This number is estimated to increase and reach to 1530000 in 2010 which means one suicide per 20 seconds (Bertolote \& Fleischmann, 2002). As far as the statistics are concerned, rates are higher in males than in females, with men three to four times more likely to kill themselves than women.

The high rate of suicide resulted in an upsurge of enthusiasm in scientific analysis of suicide according to the contributing factors. Some experts believe that suicide is often committed out of despair on the one hand and stress factors such as financial difficulties or troubles with peers on the other hand, often play a role. Two of the most influential factors regarding committing a suicide are low self-esteem and dysfunctional attitude.

Heknin et al (2010) points out that divorce, financial problems as well as troubles with families among young people are the most crucial factors regarding suicide. Buterize et al (2011) believe that financial difficulties and troubles with interpersonal relationships are the most important factors regarding suicide. Researches in Iran show that family problems, unemployment and financial difficulties are the most important factors that cause suicide among people. According to Rezayee et al (2011), suicide rate is increasing in Iran thanks to the following factors; family problems, marital problems, unemployment, struggles with relatives and some psychological disorders.

According to recent psychology researches, positive thinking and positive points of view persuade people to be optimist and hinder them to even think about suicide. for an instance Elis (1973) classifies people into two groups as rational and irrational and believes that their difference derives from their point of view. According to Elis, human behavior influences his cognition as well as his emotion; Elis (1973) also believes that human cognition can change his behavior (Kelark, 1962, quoted by Kaviani). Ineffective thinking representation and weak cognitive structure occurs when a negative event challenges ineffective schema and injured self-esteem leads to intolerance for the person that causes harmful mental and physical effects (Beck, 1976). Experts believe that self-esteem plays a very important role in having a successful adulthood. Some other researchers have shown that there is a direct relationship between self-esteem and mental health and despair (Amos, 2001) and self-esteem as well as personal effectiveness (Bertolote, 2002). Some other experts believe that selfesteem also plays a role in emotional, social and psychological adaptation. (Biabangar: 2001) 


\section{Self-esteem}

Self-esteem is a widely used concept both in popular linguistics as well as in psychology. It refers to an individual's sense of his or her value or worth, or the extent to which a person values, approves of, appreciates, prizes, or likes him or herself (Blascovich \& Tomaka, 1991). According to Fahiashtiani (2009) self-esteem is a person's overall emotional evaluation of his or her own worth. It is a judgment of oneself as well as an attitude toward the self.

Self-esteem encompasses beliefs (for example, "I am competent," "I am worthy") and emotions such as triumph, despair, pride and shame.( Hewitt, J. P. (2009). Smith and Mackie define it by saying "The self-concept is what we think about the self; self-esteem, is the positive or negative evaluations of the self, as in how we feel about it." (Smith, E. R.; Mackie, D. M. (2007). Self-esteem is sometimes defined as the evaluative dimension of the self that includes feelings of worthiness, prides and discouragement. But the most broad and frequently cited definition of self-esteem within psychology is Rosenberg's (1965), who described it as a favorable or unfavorable attitude toward the self (p. 15).

\section{Significance of the study}

Review of literature shows that few works have been reported regarding the relationship between self-esteem, dysfunctional attitude and suicide in Iran especially in Zanjan province. As far as literature review is concerned no work has been done in Mahneshan country of Zanjan about committing suicide and its relation to self-esteem dysfunctional attitude.

This study aims to consider the relationship between dysfunctional attitude and self-esteem in committing suicide. It also attempts to address the intricate relationship between low self-esteem and cognitive misunderstanding in committing suicide. More specifically this study aims to answer to the following research questions:

1. Can self-esteem prevent from committing suicide?

2. Is there any relationship between dysfunctional attitude and committing suicide?

3. How can we prevent from committing suicide?

\section{Method}

Subject

Eleven partners, who were present in the court of law for divorce in Mahneshan which is located in province of Zanjan in Iran, were chosen as the target group of the study. A sixteen-year old female who has committed suicide is chosen as subject of the study.

\section{Instrumentation}

A: A clinical interview based on DSM. IV. TR:

Based on The Diagnostic and Statistical Manual of Mental Disorders (DSM.IV.TR), published by the American Psychiatric Association, which offers a common language and standard criteria for the classification of mental disorders, a clinical interview is designed to gather data. The mentioned clinical diagnostic interview is done in two 40-mintute sessions, since there were cultural and geographical limitations.

\section{B: Coopersmith Self-Esteem Inventory}

Coopersmith designed SET according to Rogers C.R, \& Dymond, R. F (1954).This scale contains 58 items which 8 items (items $26,32,36,41,45,50,53,58$ ) are scales. SET has four subscales called general self-esteem, family self-esteem, social self-esteem and professional self-esteem.

C: Dysfunctional Attitude Scale (DAS):

The Dysfunctional Attitude Scale (DAS) is designed to measure the attitude of the subject. Dysfunctional beliefs measurement in depression was introduced by the development of the Dysfunctional Attitude Scale (Weissman and Beck 1978). The DAS was originally designed as an scale to show a general cognitive vulnerability factor to depression. However, there is some evidence to suggest that individuals vulnerable to depression may have dysfunctional beliefs only in a few, but not all, areas of their lives (e.g., Dyck 1992; Power et al. 1995, 1994; Sheppard and Teasdale 2000). Beck (1987) 
proposed that specific dysfunctional beliefs will interact with particular stressors. Therefore, it is important to focus on specific rather than general dysfunctional beliefs, in research and clinical practice. If the DAS is to be used as a marker of specific vulnerabilities, subscales of the DAS measuring specific patterns of maladaptive thinking need to be identified.

The original form of the DAS, which consists of 100 items, has been refined into two 40 -item parallel forms (i.e., DAS-A and DAS-B) by Weissman \& Beck (1979). Each item is scored from 1 to 7 which 1 is the lowest rate and 7 is the highest rate. Also, as far as The Dysfunctional Attitude Scale (DAS) is concerned, items 2,6,12,17,24, 29,30, 35,37 and 40 are calculated vice versa which means 1 is the highest rate and 7 is the lowest rate. According to DAS, 40 is the minimum and 280 is the maximum. Each number is shown with its meaning in the following:

completely agree: 7 , very agree: 6 , agree to some extent: 5 , I have no idea: 4 , disagree to some extent: 3 , very disagree:2 and completely disagree:1.

\section{Findings}

Findings of the present study show that the subject of the study had some problems in her school ages with her peer group. Interviews with her relatives declare that she had the same problems with her husband after marriage. The results obtained from questionnaire (Fathiashtiani:1995) in table 1 shows that the subject has got 26 in self-esteem which resembles low self-esteem. It should be noted that 50 is the highest score according to Fathiashtiani (1995) in self-esteem.

Table 1. self-esteem marks

\begin{tabular}{|l|l|}
\hline Self-esteem & mark \\
\hline Low self-esteem & 26 and lower \\
\hline Average self-esteem & $27-43$ \\
\hline High self-esteem & 43 and upper \\
\hline
\end{tabular}

The total of self-esteem is obtained by summing up general self-esteem, family self-esteem, social self-esteem as well as professional self-esteem.

Table 2. Detailed self-esteem marks

\begin{tabular}{|l|l|}
\hline Scale & Mark \\
\hline general self-esteem & 16 \\
\hline family self-esteem & 3 \\
\hline socail self-esteem & 5 \\
\hline professional self-esteem & 2 \\
\hline lie scale & 3
\end{tabular}

As it is seen in table 1 the subject has obtained 26 in self-esteem which shows low self-esteem. This finding of the study is in accordance with the work of Albokordi et al (2010). This study also shows that low self-esteem seems to influence marital relations. More specifically it can be said that low self-esteem leads to committing suicide of the subject of this study. Also all four subdivisions of self-esteem namely, general self-esteem, family self-esteem, social self-esteem and professional self-esteem have direct relationship with forming self-esteem in general.

Regarding DAS, table 3 shows the results: 
table 3: DAS results

\begin{tabular}{|l|l|}
\hline Scale & Total \\
\hline Vice versa & 58 \\
\hline Perfectionism & 75 \\
\hline need for social approval & 42 \\
\hline
\end{tabular}

As far as data analysis of DAS is concerned, the total mark of the subject is 175 which means a high mark that shows high cognitive misunderstanding as well as low adaptable beliefs. in another word, it can be noted that the subject faces cognitive misunderstanding that has caused her to commit suicide. This study is in accordance with Rezayee et al (2011) as well as Golding (1999).

To answer the research questions, it can be said that: regarding the first research question, 'Can self-esteem prevent from committing suicide?', the answer is yes. Since in this study, the subject has low self-esteem that caused her to commit suicide. for answering the second research question. 'Is there any relationship between dysfunctional attitude and committing suicide?', the answer is yes again. Since in this study, the subject has high cognitive misunderstanding that caused her to commit suicide. and finally about the last research question 'How can we prevent from committing suicide?', it can be pointed out that with increasing self-esteem and decreasing dysfunctional attitude, one can prevent from committing suicide.

\section{Limitations of study}

The most important limitation of the study is the fact that medical and clinical records of the subject of the study were not available. Also cultural issues made some problems for holding interviews with the subject.

\section{Suggestions}

According to the findings of the study, fallowing suggestions are presented:

- More works should be done regarding suicide and contributing factors.

- Quantative and qualative researches are suggested to be conducted.

- Some educational sessions should be held before marriage for the couples.

- Clinical centers should be more active.

- Knowing and researching dysfunctional attitude, self-esteem and contributing factors.

- Preventing from transition of dysfunctional attitude and low self-esteem to next generation

\section{References}

[1] Albokordi, S. et al (2010). Relationship between self-esteem and depression among male prisoners. Journal of Mazandaran University of Medical Sciences 20: 77 (62-68).

[2] Amos T, Appleby L (2001). Suicide and deliberate self - harm in Appleby L, Forshaw DM, Amos T, Barker H. Postgraduate psychiatry: Clinicalm and Scientific Foundations, PP 347 - 357. London: Arnold.

[3] Anisi, J. (1997). Assesment of suicide thought questionnaire. Tehran: Sina publication. \{Persian\}

[4] Ansari, A. et al (2010). Committing suicide cases and their reasons in Rafsanjan between 1385-1386. Journal of Ransanjan University of Medical and paramedical Sciences 5: 1 (38-43).

[5] Azergoon, $\mathrm{H}$. et al (2010). How effective is mind training in decreasing DAS among Isfahan University students? Psychology Journal. 4: 1 (79-94).

[6] Beck. A.T. (1976). Cognitive Therapy and Emotional Disorders. New York International university press.

[7] Bertolote JM, Fleischmann A. (2002). A global perspective in the epidemiology of Suicide. Suicidology 
[8] Elis,A.(1973).Humanistic Psychotherapy:the rational-emotive approach. New york:McGraw-Hill.

[9] Fathiashtiani, A. \& Dastani M.(2010). Psychology test. Tehran. Besat.

[10] Golding, Jacqueline, M. (1999). Intimate partner violence as a risk factor for mental disorders : A meta analysis. Journal of Family Violence 14 (2).

[11] Hampton, R. Et al (1999). Physical and sexual violence in marriage.Psychology of Family Violence. London \& Inc.

[12] Hemati, N., Daneshamooz, B. Panahi, L. (1993). Frequency of suicide among high school students of Abdanan in llam. Cognitive science findings,No.1, 2, 79-86. \{Persian\}

[13] Kelark, M.K., (1990). Cognitive behavioral therapy. Kaviani translation, Tehran, Fars publication.

[14] Kaslow, J.et al (1998). Factors that mediate and moderate the link between partner abuse and suicidal behavior in African - American woman. Journal of Consulting and Clinical Psychology 66 (3). 533 - 540 .

[15] Lin HC, et al.(2008). Depression and its association with self-esteem, family, peer and school factors in a population of 9586 adolescents in southern Taiwan. Psychiatry and Clinical Neurosciences 2008; 62: 412-420.

[16] Mills JF, Kroner DG.(2005). Screening for suicide risk factors in prison inmates: Evaluating the efficiency of the depression, hopelessness and suicide screening form (DHS). Legal and Criminological Psychology; 10: 1-12.

[17] Rezayee, A. et al (2011). Relationship between DAS and suicide among harassed partners. Women Sociology Journal. 4 : 1 (79-94). 2. 3 (123-137)

[18] Rogers,GM.Park, et al. (2009). The dysfunctional attitudes scale :Psychometric properties in depressed adolescents. J Clin Child Adolesc Psychol; 38(6):781-789

[19] Rogers, C. R \& Dymond, R. F. (1954). Psychotherapy and personality change: Coordinate studies in the client-centered approach.Chicago: University of Chicago Press.

[20] Zeinivand A.(2005). An investigation of the relationship between self esteem and social support with academic achievement of second year high school students in Darreshahr cityamong achievement year of 2004-2005. MA Thesis. Tehran: Teacher Training University.

[21] Word Health organization (2002).World Health report nonviolence and health. Geneva: WHO. 